\title{
Gender: \\ A Key Dimension of the Refugee Experience
}

\author{
by Doreen Indra
}

One of the key contemporary challenges facing the world today is to bring women into positions where they can more effectively define and shape women's perspectives, more forcefully call society's attention to women's experiences, and contribute to the evolution of a social world-view which incorporates the perspectives of both women and men. In a microcosm, the universe of refugees should reflect these same concerns. And yet, while refugees today claim a great deal of attention, women refugees do not. Hence, both researchers and aid workers involved with refugees face a strong imperative to incorporate gender issues into their work. This challenge arises from the indisputable fact that from the process of defining a refugee to the final phase of resettlement, both the overall discourse, practice, and research conceming refugees today remains primarily a male paradigm, even if in a superficial way it appears to be a universal and general one.

One can see the systematic neglect of gender as a critical consideration in every facet of the refugee situation, beginning with the popular culture image of "the refugee". As Edelman ${ }^{1}$ has noted, public images constitute one of the most profound constraints on social action, for through the power to form societal images and symbols comes the power to set the stage for formal responses to social issues. In this case the popular image of "the refugee" clearly influences the allocation of significance within the overall discourse on refugees. The image typically does not differentiate men and women as distinct kinds of refugees. Mass media materials soliciting sympathy for refugees usually tend to identify notable refugees with men, as in the popular UNHCR poster depicting Einstein as a refugee. Otherwise, the generalized image "refugee" predominates.

1 M. Edelman, Political Language: Words that Succeed and Policies that Fail (New York: Academic Press, 1977), p. xxi.
Generalized references to "refugees" obscure more than they illuminate. They obscure the ways in which gender may play a major role in how refugees are created, and how distinct the refugee situation can be for women and men. They also obscure the divergent relationships to the state and to the public realm which women and men have in source countries. Far from a politically neutral concept, the current image of "the refugee" is therefore deeply political.

To illustrate the depth of gender delegitimation in refugee contexts, consider the practical and ideological consequences of extant gender bias in definitions of a refugee. Almost universally, the following Geneva Refugee Convention criteria predominate: that a refugee is a person who "from a just fear of persecution based on race, religion, nationality, belonging to a social group or on political convictions, is outside the country of his nationality and who cannot or will not invoke the protection of this country as a result of such fears. . . [and] will not retum to his country." [italics ours]. It is remarkable that sex and gender oppression are not even mentioned, whereas oppression arising from parallel forms of invidious status distinction such as race or religious conviction are central. Thus, an individual risking death at the hands of majority group institutions for maintaining a minority religion (say, Bahá'i in Iran) fits the definition, whereas a woman (again, say in Iran) facing death by the same institutions for stepping out of her "appropriate role" or for deviating from misogynous sexual mores does not.

Many women around the world could be unambiguously considered refugees on the basis of sex and gender oppression without doing violence to the spirit of the Geneva Convention. Yet ironically, almost the opposite is sometimes the case: the attempt to maintain minority group "traditional culture" patterns which include profound sexual stratification in the face of forced state acculturation may actually be contributory grounds for the granting of refugee status.

One can go even further. As de Neef and de Ruiter 2 have eloquently shown, there exists strong international resistance to the inclusion of gender as an explicit criterion for refugee status, most particularly on the part of those states which fear that this might result in a critique of their national gender relations.

Moreover, potential male and female refugees almost never stand in the same relationship to those criteria for refugee status which at the United Nations are generally accepted -- race, religion, nationality, etc. Women sometimes have a lower probability of achieving refugee status because the key criteria for being a refugee are drawn primarily from the realm of public sphere activities dominated by men. With regard to private sphere activities where women's presence is more strongly felt, there is primarily silence - silence compounded by an unconscious calculus that assigns the critical quality "political" to many public activities but few private ones. Thus, state oppression of a religious minority is political, while gender oppression at home is not. In addition, "oppression". itself has strong gender implications: physical violence, cultural, political, and religious intolerance all have their distinctly genderized consequences.

Likewise, the process of flight has strong gender implications. Sometimes scarce resources that make flight possible are preferentially allocated to men by culture, gender role constraints, and context. When in flight (an eminently "public" activity) men may also command superior

2 C.E.J. de Neef and SJ. de Ruiter, Serual Violence Against Women Refugees (Amsterdam: Ministry of Social Affairs and Labour, 1984). 
moral resources by virtue of local expectations that men may travel without the "protection" of kinsmen, but that women should not; in some countries women not so "protected" fall prey to a host of difficulties: sexual violence, kidnapping, robbery, enslavement, death. Similarly, the agents of the various states and agencies with whom refugees in flight deal -- those of the source and host countries, aid workers, etc. - are predominantly men (especially those in positions of power), with the result that gender relations are a critical dimension of refugee flight.

The salience of gender is no less high for refugees in camps. The organization of camps is often predicated on the family unit as the primary building block of the system distributing goods and services to individual refugees. Although there àre many benefits to using the social category of family in this context, the gender implications must be seen more clearly than they are at present. To do otherwise is to consign women's concerns to the shadows of the private world and to the periphery of refugee policy and practice. Moreover, a camp's typical emphasis on males as family spokepersons and as brokers between refugees and (primarily male) camp functionaries guarantees the close identity of public camp discourse on "family" or "refugee" concerns with the concerns of certain men. Relief distribution systems can thereby become highly politicized along the lines of gender. The same can be true of "traditional culture" when operating in the camp context; for example, the tradition of men and (male) guests eating before women and children has traditionally allocated a superior diet to men in many cultures; in refugee contexts the consequences of this practice for women can be severe.

It is relatively rare that in those cases where there are serious efforts to resettle refugees in Western countries the formal criteria of selection overtly discriminate against women. And yet in this process women often suffer from many of the same gender-based disabilities that they would face in their home country: men and women in virtually every refugee source country have different relationships of production. Men likewise are likely to have significantly superior competitive class resources: education, literacy, occupational skills, public sphere interaction skill, etc. This differential, combined with the routine identification by selection officers of "heads of household" with men mean that women primarily move to resettlement in third countries as dependents of male kin and with inferior class resources.

During the actual process of settlement in third countries control over the definition of the refugee situation shifts from international agencies primarily to the third country state and its associated social welfare system. All such states are gender stratified in varying degrees.

But what impact does this have on refugee resettlement? Initially, neither male nor female refugees constitute a significant pressure group in respect to the conditions of their own resettlement; they are defined by the system rather than being definers of it, and societal patterns of social welfare are consequently mapped over onto refugees largely unchanged. This is doubly the case for refugee women, who, in addition to suffering the disabilities of being a refugee are further constrained by being women; they often lack the class and cultural resources to make their concerns heard, and they are constrained from protesting by both traditional gender roles and by altruistic considerations of the marginal psychological statuses of their men. They thus suffer from two levels of gender inequality; that of their host country context and that of their source culture.

Inevitably, the overall practical consequence is that settlement proceeds on the (obvious, but possibly incorrect) thesis that these people are refugees first and women or men second; if one considers that in such third countries there is virtually no significant social, political or cultural context in which any other dimension of a person's self is of greater import than gender, one might at least occasionally consider the situation in reverse: that these people are men and women who happen to be refugees. To do so might make far greater sense out of many patterns of practical refugee programming.

From a research point of view, it is clear that if gender is to be apportioned its proper weight in understanding how refugees are created, the social organization of the camps, camp and third country social service delivery systems, and immigrant community structure, a new, gender-informed perspective must come from far more than just inductive empirical observation. Irrespective of their disciplines, researchers may also consider that their academic paradigm itself is at least partially a reflection of extant societal values, and of societal allocation of salience to certain social issues and social problems rather than others. To the extent that these forces enter into research paradigms, they usually delegitimate gender issues. This occurs also through an unconscious research bias towards the analysis of formal structures like community organizations, towards named statuses like ethnic group spokepersons, and towards abstract conceptions of social life, such as ideal models for the family. The necessary corrective is essentially the same as it is across the social sciences: irrespective of topical focus, one must place gender at the centre of the analysis. It is critical therefore to be conscious when researching "refugees", "refugee communities", "refugee culture", and "refugee concems" to ask the appropriate gender-linked questions: what refugee, whose community, culture or concem?

Doreen Indra, an anthropologist at the University of Lethbridge, recently coedited Uprooting, Loss, and Adaptation: Southeastern Refugees in Canada, being published by the Canadian Public Health Association. 